\title{
Agôn
}

Revue des arts de la scène

Critiques | Saison 2013-2014

\section{Masculin / Féminin, mise en scène de Julie Duclos, Rapport sur moi de Grégoire Bouillier, mise en scène de Matthieu Cruciani}

Théâtre et saisissement

\section{Caroline Châtelet}

\section{OpenEdition}

\section{Journals}

Édition électronique

URL : http://journals.openedition.org/agon/3062

DOI : $10.4000 /$ agon.3062

ISSN : 1961-8581

\section{Éditeur}

Association Agôn

\section{Référence électronique}

Caroline Châtelet, « Masculin / Féminin, mise en scène de Julie Duclos, Rapport sur moi de Grégoire Bouillier, mise en scène de Matthieu Cruciani », Agôn [En ligne], Critiques, mis en ligne le 16 juin 2014, consulté le 23 septembre 2020. URL : http://journals.openedition.org/agon/3062 ; DOI : https:// doi.org/10.4000/agon.3062

Ce document a été généré automatiquement le 23 septembre 2020 


\title{
Masculin / Féminin, mise en scène de Julie Duclos, Rapport sur moi de Grégoire Bouillier, mise en scène de Matthieu Cruciani
}

Théâtre et saisissement

\author{
Caroline Châtelet
}

\section{RÉFÉRENCE}

Masculin / Féminin mise en scène de Julie Duclos - compagnie l'In-quarto - du vendredi 30 mai au dimanche 1er juin, festival Théâtre en mai, à Dijon /// Rapport sur moi de Grégoire Bouillier, mise en scène de Matthieu Cruciani - du vendredi 30 mai au dimanche 1er juin, festival Théâtre en mai, à Dijon /// www.tdb-cdn.com

Dans l'édito de l'édition 2014 de Théâtre en Mai' ${ }^{1}$, le metteur en scène Benoît Lambert et le comédien Emmanuel Vérité affirmaient la volonté d'un festival tout à la fois «insolent, curieux, rageur, provocateur, enthousiaste, insurgé, joyeux, lumineux, amoureux. Profondément libre. »Si l'envie d'amender ou de prolonger cette liste d'adjectifs a pu traverser nombre de spectateurs au sortir de spectacle(s) du festival, un terme semble particulièrement bien compléter l'énumération. Un seul, quitte à décliner sa racine et ses sens. Car entre Masculin / Féminin mis en scène par Julie Duclos et Rapport sur moi de Grégoire Bouillier mis en scène par Matthieu Cruciani - et quoique les deux créations soient irréductibles l'une à l'autre -, ce sont bien les questions du saisissement (d'un sujet), du saisissable (d'une démarche) comme de l'insaisissabilité (d'une forme) qui sont abordées par l'un ou l'autre de ces deux spectacles. Avec plus ou moins de bonheur... Pour Masculin / Féminin, la compagnie In-Quarto et la metteuse en scène Julie Duclos ont souhaité embarquer les spectateurs au cœur du processus de travail pour interroger les notions de masculin et, donc, de féminin. Ainsi, c'est côté 
jardin que le public entre dans la salle, traversant l'espace scénique pour pouvoir atteindre les gradins. Bureau de travail, salon, chambre spartiate, salle de réunion sont autant d'espaces ménagés sur le plateau et que les comédiens investiront (ou seulement traverseront) au cours du spectacle. Là, d'un lieu à l'autre va s'enchaîner diverses séquences. Textes, musiques, images, vidéos, qu'il s'agisse de propos personnels des comédiens ou de références littéraires et artistiques variées, se suivent dans un jeu de kyrielles plus ou moins décousu. Mais après une ouverture plutôt intrigante, où se succèdent un enregistrement de petite annonce d'escort-girls, une interview, toujours, d'escort-girl, puis un extrait de numéro de danse, le temps se dilate. La tension initiale s'effiloche, les saynètes se suivent sans puissance ni présence. Comme si la structure et le propos même du spectacle échappait à l'équipe, Masculin / Féminin se borne à égrener les situations sans réelle direction. De ce qu'on supposait initialement - des interrogations sur les concepts de masculin et de féminin - l'ensemble dérive vers des problématiques liées à l'amour et au couple. Quoique cousines, toutes ces thématiques peinent à s'articuler ensemble pour structurer un propos. Ne reste que le spectacle d'une équipe submergée par ses envies et idées, et à l'heure actuelle encore incapable de se saisir de son sujet.

Pour Rapport sur moi de la compagnie The Party, le saisissement résonne comme l'une des lignes de force du projet. Car mettant en scène ce texte à mi-chemin entre l'autofiction et le roman, le récit et l'autobiographie, Matthieu Cruciani en travaille toute la part d'insaisissable. Dans ce livre, le premier de son auteur (couronné du prix de Flore en 2002), Grégoire Bouillier se livre à un regard rétrospectif, de la rencontre de ses parents à sa naissance en 1960 à Tizi-Ouzou en Algérie, jusqu'à ses premiers jobs et expériences amoureuses. Balayant trente années de façon tout sauf linéaire, Rapport sur moi procède bien à sa façon du rapport, « action de raconter ce que l'on a vu, ce que l'on a entendu ». Avec une distance et une dérision réjouissante, Grégoire Bouillier fait de ses souvenirs fiction et retisse entre eux les fils invisibles. L'ouvrage et le spectacle, en s'ouvrant et se fermant tous deux sur une tentative de suicide de sa mère, racontent également la façon dont Grégoire Bouillier a su se saisir du langage (et surtout de la littérature) pour se construire. Ainsi, à la gravité du suicide introductif déclenché par une phrase malheureuse de Grégoire à sa mère répond la réplique réparatrice finale, toujours de Grégoire à sa mère. Entre les deux il y aurait le bonheur annoncé, mais surtout toutes les déconvenues, déboires, ratés et petites victoires qui font une vie. Mettant en scène ce texte truffé de jeux de langues et autres clins d'œils lacaniens, Matthieu Cruciani et son équipe dépassent la seule transposition. Se saisissant du texte et de sa structure méandreuse, ils composent une forme mouvante, entre théâtre et concert. Nous assistons à ce qui ressemble à une répétition de groupe de rock, les Klongs. Un guitariste chevelu, une chanteuse pianiste et Grégoire, batteur génialement interprété par Pierre Maillet préparent des morceaux. Entre les bribes musicales Grégoire parle, s'adressant à la salle ou échangeant avec ses deux comparses. Mais on ne saura jamais véritablement qui est qui, qui fait quoi. À l'indéfini de leur(s) personnage(s) répond l'indéterminé de l'espace scénique : fond de scène évoquant pour moitié un vague local de répèt' de groupe de rock (avec ses boîtes à œufs sensées insonoriser et son canapé), intérieur bourgeois renvoyant à quelques épisodes de la vie de Grégoire (avec fauteuils et canapé, encore), espace indéfinissable où se vivent les échappées sur fond d'image sylvestre... Si le dispositif, la création lumière raffinée, la présence précise et versatile des comédiens, tout comme la musique participent de la structure louvoyante et sinueuse de la création, c'est bien le texte qui architecture le 
spectacle. Passant du témoignage âpre et violent - tel le récit du viol par son frère -, à la réflexion mûrie - comme le sauvetage par la littérature via la découverte de L'Odyssée - le récit bascule du prosaïsme à la froideur, de la gaieté à la réflexion fournie sur les rapports entre réel, réalité, réalisme et vérité. En s'emparant théâtralement des caractéristiques de Rapport sur moi, la mise en scène de Matthieu Cruciani offre un spectacle insaisissable et ondoyant, à la densité et au mystère prégnants. Une création maîtrisée, sans volontarisme spectaculaire, et qui révèle autant qu'elle amplifie la parole mouvante, ironique et profondément inquiète de Grégoire Bouillier.

Rapport sur moi

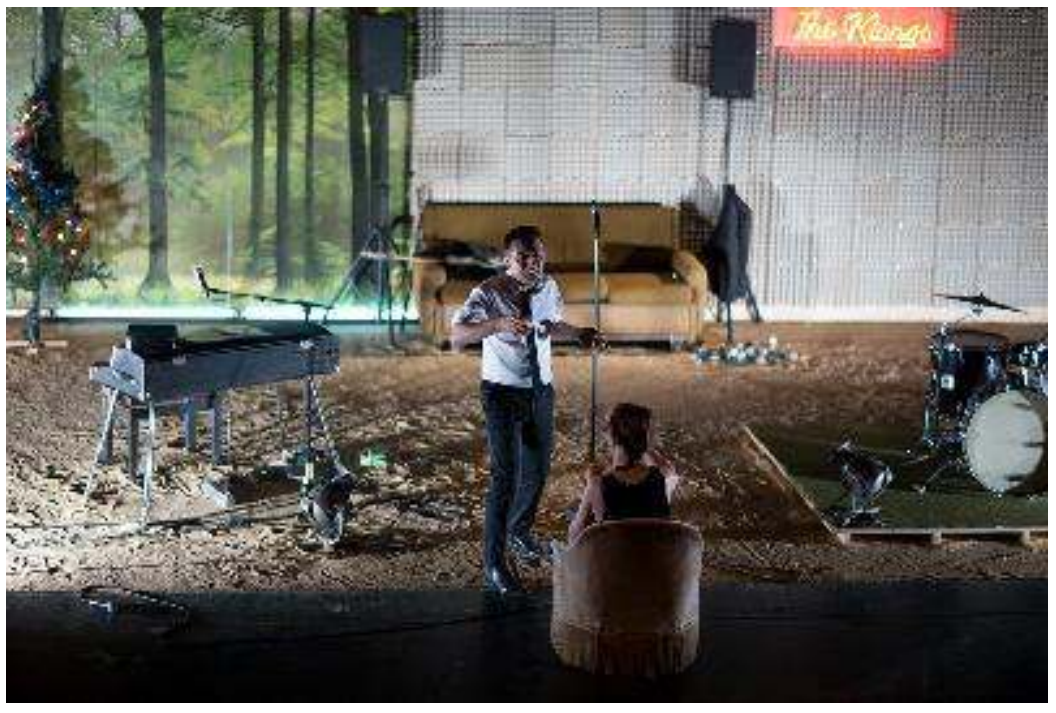

(C) Vincent Arbelet 
Masculin / Féminin

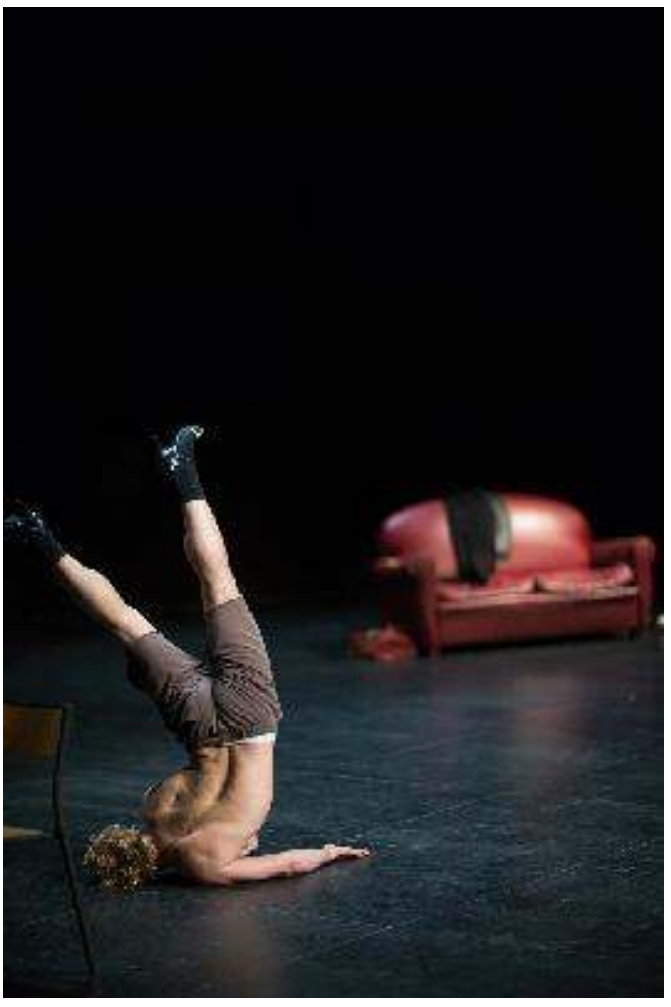

(C) Vincent Arbelet

\section{NOTES}

1. http://www.tdb-cdn.com/theatre-en-mai-25eme-edition 